\title{
Farklı Kaynak Parametrelerinde Sürtünme Kaynağı ile Birleştirilmiş AISI304/AISI5140 Çelik Çiftlerinin Mekanik ve Mikroyapılarının Araştırılması
}

\author{
Edip ÇETKIN* \\ Batman Üniversitesi, Elektrik ve Enerji Bölümü, Batman, Türkiye \\ (ORCID: 0000-0002-0217-5897)
}

\begin{abstract}
Öz
Yapılan çalışmada 1500, 1700 ve 1900 dev/dak devirlerinde ve 4, 6 ve 8 saniye sürtünme sürelerinde, sürtünme kaynak metodu ile AISI 304 paslanmaz çeliği ile AISI 5140 çeliğin birleşimi yapılmıştır. Birleşimi yapılan çelik çiftlerinin kaynak bölgeleri ve esas malzemelerin SEM görüntüleri alınmış olup, ayrıca kaynak için önemli olan bu bölgelerin mikrosertlik ölçümleri de yapılmıştır. Son olarak ASTM E8 standardına uygun olarak hazırlanan kaynaklı numuneler çekme yüküne tabi tutulmuştur. Sonuç olarak 1900 dev/dak devirde ve 8 saniye sürtünme süresinde yapılan birleştirmelerin ara kesitinde alınan numunenin SEM görüntüsünde daha düzgün bir birleşmenin olduğu ve bunun sonucunda çekme testlerinde de en iyi sonuçlar elde edildiği görülmüştür.
\end{abstract}

Anahtar kelimeler: AISI 304, AISI 5140, çekme testi, sürtünme kaynağ1.

\section{Investigation of Mechanical and Microstructures of AISI304/AISI5140 Steel Pairs Joined by Friction Welding at Different Welding Parameters}

\begin{abstract}
In this study, AISI 304 stainless steel and AISI 5140 steel were joined in 1500, 1700 and $1900 \mathrm{rpm}$ and 4, 6 and 8 seconds of friction times by friction welding method. Weld regions of the connection steel pairs and SEM images of the main materials were taken and microhardness measurements of these regions which were important for welding were also performed. Finally, welded specimens prepared in accordance with ASTM E8 were subjected to tensile load. As a result, it was seen that the SEM image of the specimen taken in the cross-section of the joints made at $1900 \mathrm{rpm}$ and 8 seconds friction time had a good joining, and as a result, the best results were obtained in tensile tests.
\end{abstract}

Keywords: AISI 304, AISI 5140, tensile test, friction welding.

\section{Giriş}

Birleştirme, imalatın önemli bir alanıdır. Metal esaslı malzemelerin birleştirilmesi için çeşitli birleştirme teknikleri kullanılmaktadır. Bunlardan biri de bir katı hal kaynak yöntemi olan sürtünme kaynağıdır. Sürtünme kaynağı, aynı eksen üzerinde birbirileri ile temas edecek düzeye getirilmiş aynı veya farklı cinsten ve genellikle silindirik geometriye sahip iki parçanın alın alına sürtünmeyle meydana gelen ısıdan faydalanarak parçaların sürtünme yüzeylerinde parçaların birleşiminin sağlandığı bir katı hal kaynak metodudur. Sürtünme kaynağı ile birleştirme işleminde alın alına sürtünen yüzeyler arasında tam bir birleştirme işleminin sağlana bilmesi için bu parçalar belirli bir basınç altında olması gerekir. $\mathrm{Bu}$ işlem birleşimi sağlanacak parçalar için gerekli olan plastik şekil değişimi sıcaklığına erişene kadar devam eder. Daha sonra plastik şekil değişimi için gerekli olan ısıyı oluşturan basınç artırılarak birleşimi yapılacak parçaların ara yüzeylerinde 1sıtılmış metal dışarıya doğru yığılır. Böylece birleşim bölgesi termo-mekaniksel bir işleme tabi tutulmuş olur ve bu bölgede iyi bir tane yapısı elde edilmiş olur [1].

*Sorumlu yazar: edip_cetkin@ hotmail.com

Geliş Tarihi: 06.01.2020, Kabul Tarihi: 29.04.2020 
Sürtünme kaynağı işleminde TIG, MIG ve MAG kaynağı gibi yöntemlerinde kullanılan ilave tel ve koruyucu gaza gerek yoktur. Bunu ile beraber birbiri ile aynı eksende ve alın alına dönen silindirik parçaların birleştirilmesinde kullanılan bir kaynak yöntemi olan sürtünme kaynağının birçok avantajları vardır. Bunlar; kaynak işlemi için ihtiyaç olan enerjinin küçük olması, birleştirme işleminin kısa olması ve işlemin tam otomatik olarak yapılabilmesi, geleneksel kaynak işleminde olduğu gibi ekstradan malzemeye ihtiyaç duyulmaması ve bu metot ile aynı cinsten parçaların kaynağının yapılabildiği gibi farklı cinsten parçaların kaynağı da yapılabilmektedir [2-4].

Ünal ve ark. (2019), Sürtünme kaynak metodunu kullanarak farklı kaynak parametrelerinde birleştirilen AISI 3161 /AISI 4140 malzemelerinin ara yüzeyinde oluşan mikroyapıyı araştırmışlardır. Araştırmacılar düşük dönme devirin de birleşmenin olmadığını ve dönme devrinin artmasıyla karıştırma bölgesinde deformasyonların artı̆̆ını belirtmişlerdir. Ayrıca dönme devrinin artmasıyla birleşme bölgesinde mikrosertliğinde artığını vurgulamışlardır [5]. Sahin ve ark., (2004), AISI 304 paslanmaz çeliği ile 1040 orta karbonlu çeliğini farklı sürtünme basıncı ve farklı sürtünme zamanı kaynak parametrelerini kullanarak sürtünme kaynağı metodu ile birleştirmişlerdir. Daha sonra elde edilen kaynaklı numunelerin mekanik testleri ve mikroyapı incelemelerini yapmışlardır. Sonuç olarak kaynak parametre kombinasyonunun birleşiminin mikroyapı ve mekanik testleri üzerinde önemli bir etkisinin olduğunu belirtmişlerdir [6]. Chludzinski ve ark. (2017) $220 \mathrm{~mm}$ çapında ve $8 \mathrm{~mm}$ et kalınlığına sahip boru çiftlerini $12.7 \mathrm{~mm}$ et kalınlığına sahip ara halka kullanarak sürtünme kaynă̆ 1 metodu ile birleştirmeler yapmışlar. Daha sonra mikroyapı, mikrosertlik ve kırılma tokluğu testlerini yapmışlardır. Testler neticesinde kaynak merkezinde maksimum sertliklerin elde edildiği ve 1s1 etkisi altındaki bölgelerde düşüşlerin olduğunu, mikroyapı görüntülerinde ise kaynak merkezinde aşırı 1sınmış mikroyapılan olduğunu ve son olarak kırılma tokluğun ise 1sı etkisi altındaki bölgede (ITAB) azaldığını belirtmişleridir [7]. Sathiya ve ark. (2008) eşit çapta ve eşit uzunlukta östenit ve ferit paslanamaz çeliklerini farklı kaynak parametrelerinde sürekli tahrikli bir sürtünme kaynak makinesini kullanarak sürtünme kaynağ ile birleştirmişlerdir. Daha sonra kaynağı yapılan parçaların mikroyapı, mikrosertlik ve çekme testlerini yapmışlardır. Sonuç olarak fazla ısı girdisinin mikroyapıda tane irileşmesine neden olduğunu buna bağlı olarak kaynaklı paraların çekme mukavemetinin ve mikrosetliğin de bundan etkilediğini vurgulamışlardır [8]. Taban ve ark. (2010), Geleneksel kaynak metodu ile birleşimi zor olan $12.5 \mathrm{~mm}$ çaplarında AISI 1018 çeliği ile AA6061-T6 alüminyum alaşımını farklı kaynak parametrelerinde sürtünme kaynağı ile başarılı bir şekilde kaynak etmişlerdir. Elde edilen kaynaklı numunelerin mekanik testleri ve mikroyapı analizlerini yapmışlardır. $250 \mathrm{MPa}$ bağlantı mukavemetlerini elde etmişlerdir. Mikroyapı görüntülerinde alüminyum tarafinda daha fazla plastik deformasyonların olduğunu ve burada ince taba şeklinde Al-Fe intermetalik oluşumunu gözlemlemişlerdir. Ayrıca bu ara yüzeylerde çeliğin ve alüminyumun sıcaklıklarını sırasıyla 420-370 ${ }^{0} \mathrm{C}$ olarak ölçmüşlerdir [9]. Çelik ve ark. (2008), AISI 4140 ve AISI 1050 çeliklerini sürtünme kaynağ1 ile birleşimi yapmışlardır. Daha sonra elde dilen numunelerin mikroyapı, makroyapı ve mekanik özeliklerini araştırmışlardır. Makroyapı gözlemlerinde sürtünme basıncı ve sürtünme zamanına bağlı olarak paralel bir şekilde parçaların flaşlarının artığını gözlemlemişlerdir. Ayrıca AISI 1050 çeliğin flaşların daha uzun olduğunu da belirtmişlerdir. Mikroyapı görüntülerinde ise optimal parametrelerde birleşim bölgelerinde iyi bir yapı elde etmişlerdir. Çekme testlerinde ise bütün kopmaların AISI 1050 çeliğinde meydana geldiğini ve Maksimum çekme mukavemetini 1073.9 MPa olarak elde etmişlerdir [10].

Literatür çalışmalarında optimum kaynak parametrelerinin, kaynağı yapılan parçaların makroyapı ile mikroyapının görüntü analizleri ve mekanik testleri üzerinde önemli bir etkisinin olduğunu belirtmişlerdir. Ayrıca aynı ve farklı cinsteki malzemelerin başarılı bir şekilde yapılabildiğini de vurgulamışlardır. Bu çalışmada ise; literatürde daha önce kullanımı bulunmayan ve geniş bir kullanım alanı olan farklı özelikteki AISI 304 paslanmaz çeliği ile AISI 5140 sslah çeliği farklı dönme devri ve farklı sürtünme zamanlarında sürtünme kaynağı ile birleştirilerek; mikrosertlik ölçümleri, çekme testleri ve kaynak ara yüzeyde oluşan mikroyapısal değişimleri inceleyerek bu doğrultuda en uygun kaynak parametrelerinin belirlenmesi amaçlanmıştır.

\section{Materyal ve Metot}

Çalışmada imalat sanayisinde ve endüstrinin çeşitli dallarında yaygın bir kullanımı olan farklı mekanik özeliklere ve farklı kimyasal bileşime sahip olan AISI 304 ve AISI 5140 çelikleri kullanılmıştır. AISI 
304 malzemesi kullanımı en aygın olan paslanmaz çeliği türüdür. 400 0C'ye kadar yüksek oksidasyona sahip olup, mekanik dirençleri ve sürtünme mukavemetleri yüksektir. Gıda, otomotiv, ev eşyası, petrokimya ve tıp endüstrisinde yaygın bir şekilde kullanılmaktadır. AISI 5140 çeliği ise orta karbonlu olup krom $(\mathrm{Cr})$ alaşımlı veya yüksek dayanımlı düşük alaşımlı ıslah çeliğidir. Otomobil, motor parçaları, krank mili inşaat, ziraat ve takım tezgâhlarında kullanılmaktadır. Ayrıca yüzey sertleşmeye uygun bir malzemedir. Tablo 1'de bu iki çeliğin kimyasal bileşimleri verilmiştir.

Tablo 1. AISI 304 paslanmaz çeliği ve AISI 5140 çeliğin kimyasal bileşimleri

\begin{tabular}{|l|c|c|c|c|c|c|c|c|c|c|c|c|}
\hline & \multicolumn{10}{|c|}{ Alaşım Elementleri (\%) } \\
\cline { 2 - 15 } Malzeme & $\mathrm{C}$ & $\mathrm{Si}$ & $\mathrm{Mn}$ & $\mathrm{P}$ & $\mathrm{S}$ & $\mathrm{Cr}$ & $\mathrm{Mo}$ & $\mathrm{Ni}$ & $\mathrm{Al}$ & $\mathrm{Cu}$ & $\mathrm{W}$ & $\mathrm{Fe}$ \\
\hline AISI 304 & 0.04 & 0.33 & 1.54 & 0.04 & 0.03 & 18.26 & 0.39 & 8.41 & 0.02 & 0.68 & 0.09 & 70.17 \\
\hline AISI 5140 & 0.42 & 0.28 & 0.75 & 0.04 & 0.04 & 1.05 & - & - & - & 0.35 & - & 97.07 \\
\hline
\end{tabular}

Sürtünme kaynağında kullanılan AISI 304 ve AISI 5140 çelikleri kaynağı öncesi 12 mm çapında ve $85 \mathrm{~mm}$ boyunda torna tezgâhında işlenerek kaynağa uygun hale getirilmiştir. Numunelerin kaynak işlemleri, Tablo 2'de ki kaynak parametreleri kullanarak sürekli tahrikli sürtünme kaynak makinesinde Şekil 1'de gösterildiği gibi gerçekleştirilmiştir. Kaynak sonrası, numunelerin kaynak bölgelerinde meydana gelen mikroyapısal değişimleri incelemek amacıyla numunelerin kaynak hattına dik doğrultuda kesilerek, yüzeyleri taşlanıp, 80, 220, 400, 600, 800 ve 1200 zımpara taşı ile temizlenmiştir. Daha sonra $3 \mu \mathrm{m}$ 'lik elmas pasta ile parlatılmıştır. Parlatılan numuneler nitrik \%30 HNO3+ \%20 HF asit+ \%50 H2O çözeltisiyle dağlanmıştır. Dağlanan numunelerin elektron mikroskobunda mikroyap1 fotoğrafları alınmıştır. Mikrosertlik ölçümleri, Shimadzu HMV mikrosertlik ölçüm cihazında yapılmıştır. Ölçümlerde; numunelere, $1 \mathrm{~mm}$ ölçüm aralıklarında $1 \mathrm{~N}$ yük uygulanmış ve Vickers (HV0.1) sertlik ölçüm birimi kullanılmıştır.

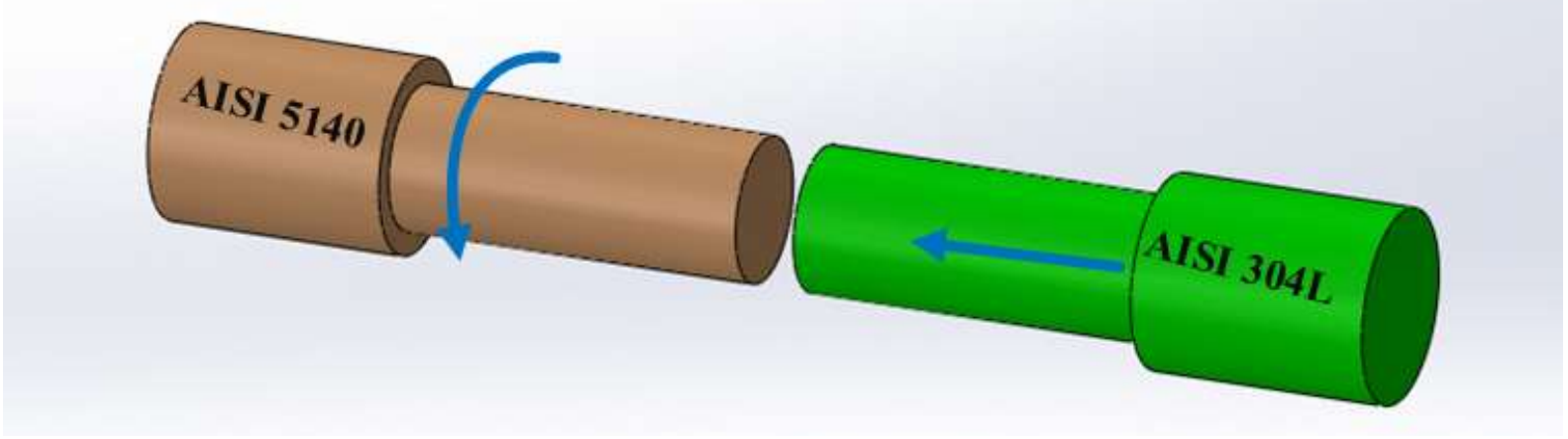

Şekil 1. Sürtünme kaynağı yapılan parçaların düzeneği

Tablo 2. Kaynak işleminde kullanılan parametreler

\begin{tabular}{|l|l|l|l|l|l|}
\hline Numune no & $\begin{array}{l}\text { Devir say1s1 } \\
\text { (dev/dak) }\end{array}$ & $\begin{array}{l}\text { Sürtünme } \\
\text { basınc1 }(\mathrm{MPa})\end{array}$ & $\begin{array}{l}\text { Yiğma } \\
\text { basinc1 } \\
(\mathrm{MPa})\end{array}$ & $\begin{array}{l}\text { Sürtünme } \\
\text { süresi (sn) }\end{array}$ & $\begin{array}{l}\text { Y1ğma } \\
\text { süresi (sn) }\end{array}$ \\
\hline S1 & 1500 & 40 & 80 & 4 & 12 \\
\hline S2 & 1700 & 40 & 80 & 4 & 12 \\
\hline S3 & 1900 & 40 & 80 & 4 & 12 \\
\hline S4 & 1900 & 40 & 80 & 6 & 12 \\
\hline S5 & 1900 & 40 & 80 & 8 & 12 \\
\hline
\end{tabular}

Tablo 2'de verilen parametreler kullanarak kaynakların yapıldığı sürekli tahrikli kaynak makine Şekil 2'de verilmiştir. 


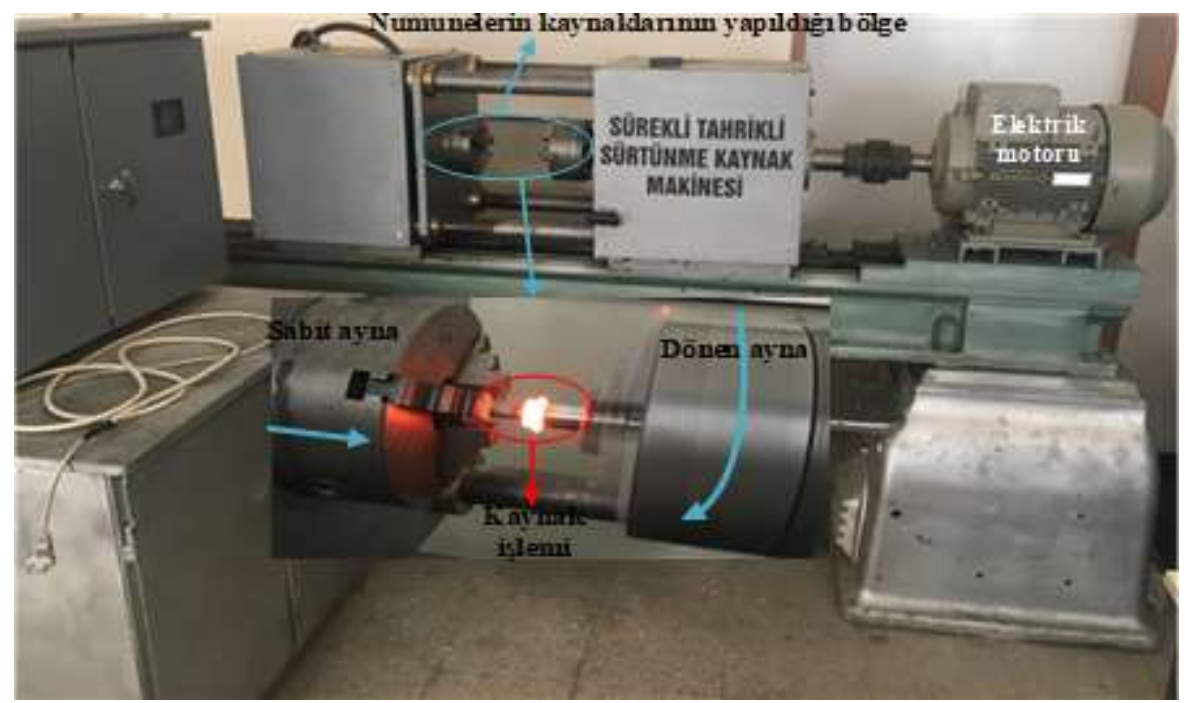

Şekil 2. Sürtünme kaynakların yapıldığı sürekli tahrikli kaynak makinesi

Şekil 3'te sürtünme kaynak metodu ile kaynakları yapılan AISI 304 paslanmaz çeliği ile AISI 5140 çeliğin toplu gösterimi verilmiştir.

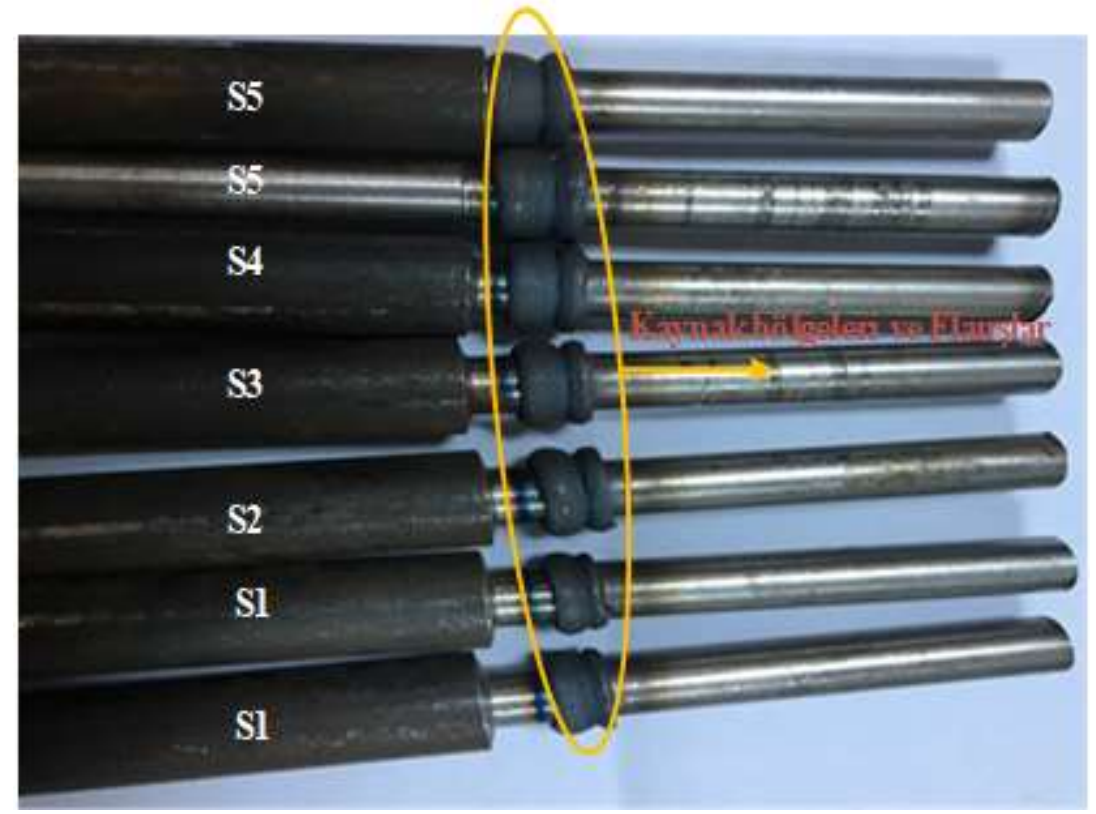

Şekil 3. Kaynakları yapılan numuneler

Kaynaklı bağlantıların maksimum çekme kuvvetlerini belirlemek için Şekil 4'te verildiği ASTM E8 standardına uygun olarak numuneler hazırlanmıştır. Daha sonra Şekil 5'te verildiği gibi 250 KN yük kapasitesine sahip SHMADZU marka çekme test cihazında $1 \mathrm{~mm} /$ dak sabit ilerleme hızında çekme deneyleri gerçekleştirilmiştir.

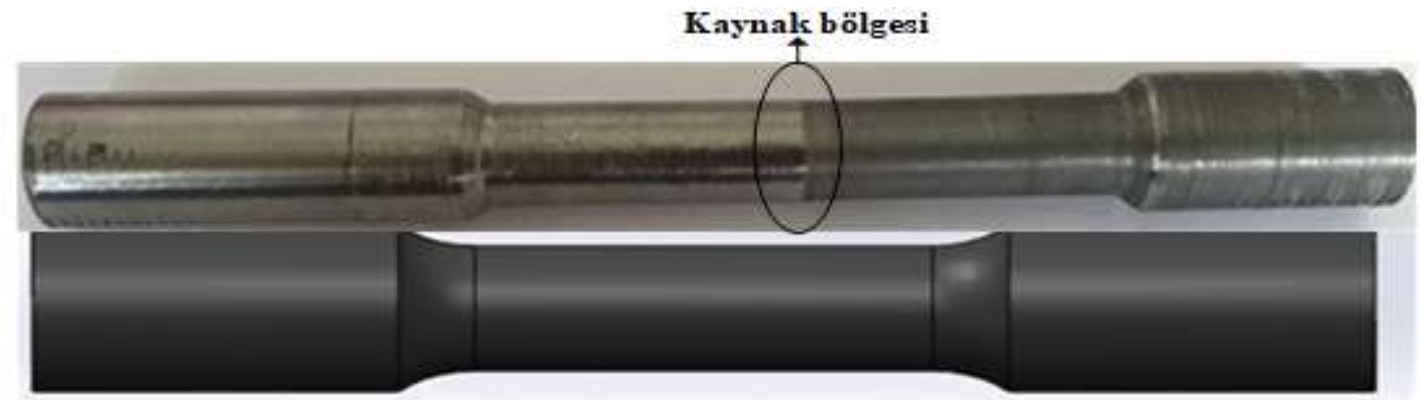

Şekil 4. ASTM E8 göre hazırlanan çekme test numunesi ve Solidworks katı modeli 


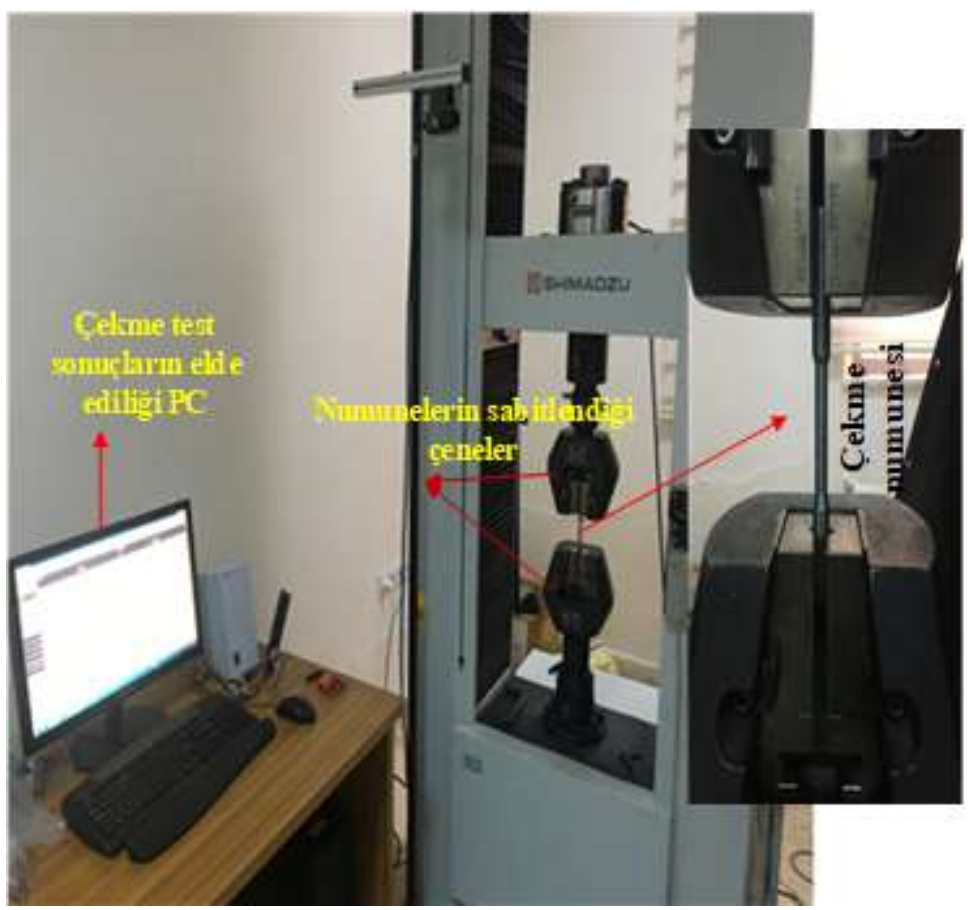

Şekil 5. Çekme testlerin yapıldığı SHIMADZU marka çekme cihazı

\section{Bulgular ve Tartış̧ma}

Sürtünme kaynak metodunu kullanarak 1500, 1700 ve 1900 dev/dak dönme devri ve 4, 6 ve 8 saniye sürtünme süresi parametrelerinde AISI 304 paslanmaz çeliği ile AISI 5140 çeliğin birleşimi yapılmıştır. Daha sonra birleşimi yapılan çeliklerden alınan numuneler ile kaynak bölgelerinde parametrelerinin etkisini irdelemek için SEM görüntüleri alınmıştır. Sürtünme kaynağının kaynak parametrelerinin kaynak bölgelerinin sertlik değerleri üzerindeki değişimini görmek için mikrosertlik ölçümler yapılmıştır. Son olarak da çekme kuvveti altındaki reaksiyonları öğrenmek içinde çekme test işlemleri yapılmıştır.

\subsection{Mikroyapı görüntüleri}

Şekil 6'da S1 numaralı numune üzerinde sürtünme kaynağı sonrasında oluşan bölgelerim SEM görüntüleri detaylı bir şekilde verilmiştir. Şekil 7'de ise hem S1 hem de S5 nolu numunenin sürtünme kaynağı sonrası oluşan bölgelerin mikroyapı görüntüleri verilmiştir.

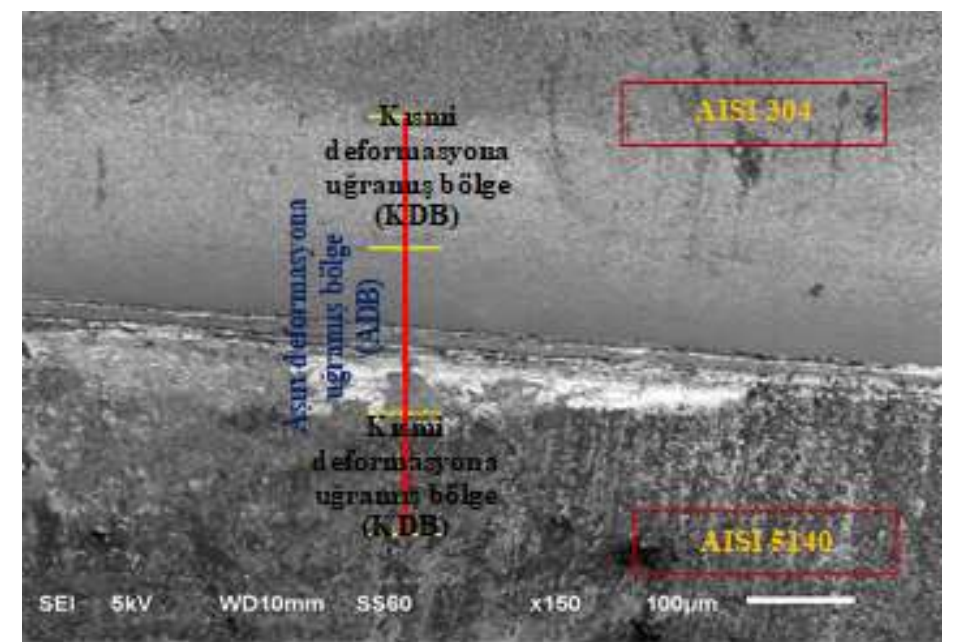

Şekil 6. S1 numunesinin kaynak arakesitinde oluşan bölgeler 

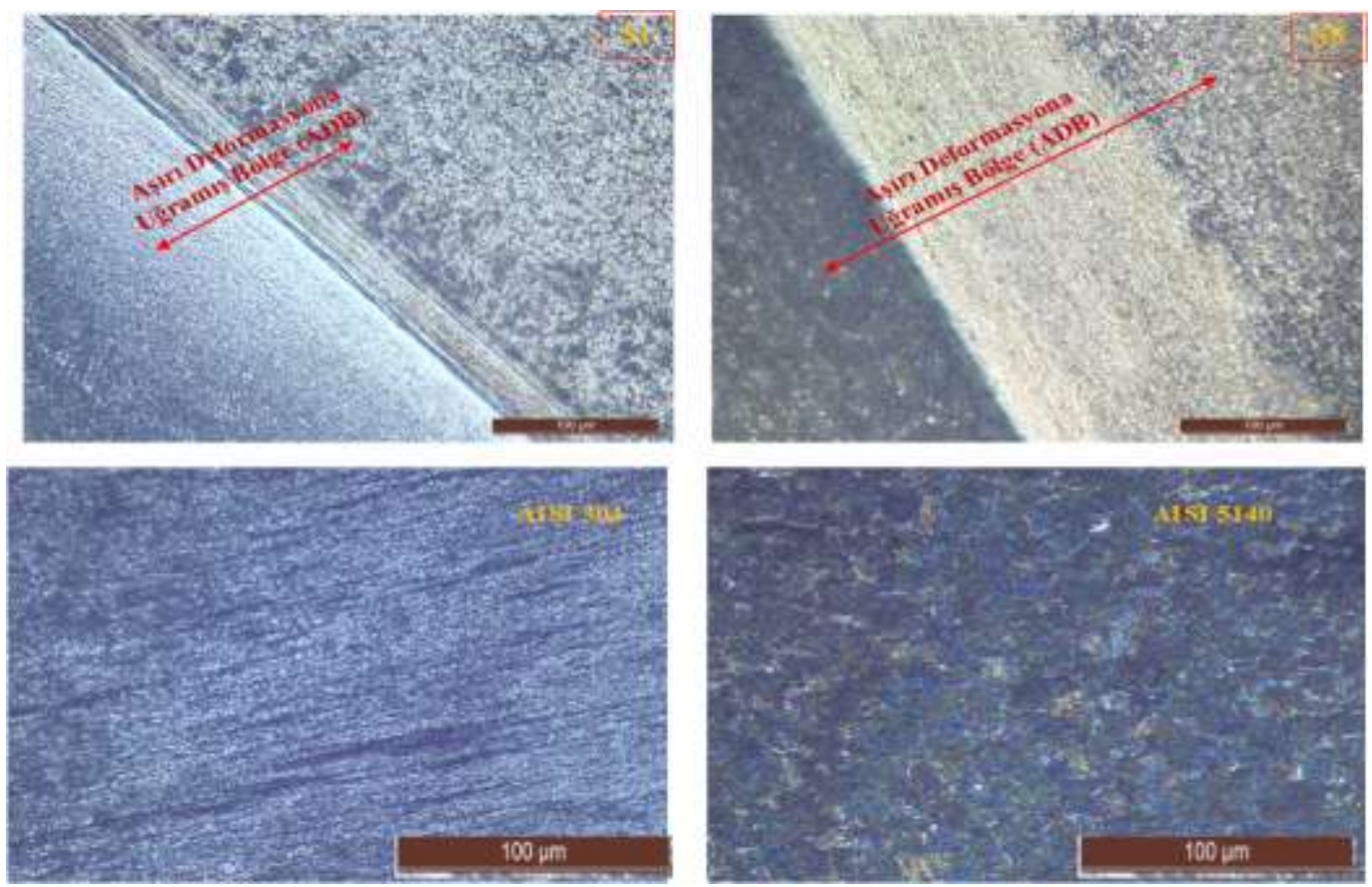

Şekil 7. S1 ve S5 nolu numunelerin mikroyap1 görüntüleri

S1 ve S5 nolu numunelerinin sürtünme basınc1 ve yığma basıncı sabit alınarak farklı devir ve sürtünme sürelerinde yapılan sürtünme kaynaklarının SEM ve mikroyapı görüntülerine bakıldığında aşırı deformasyona uğramış bölge (ADB) ve kısmı deformasyona uğramış bölgenin (KDB) belirgin bir şekilde oluştuğu görülmektedir. S1 nolu numunenin ADB bölgesinin arakesitine bakıldığında kaynağın gerçekleştiği fakat birleşme ara yüzeyinde çatlak şeklinde kaynak dönme devri yönünde bağlantısız bölgelerin oluştuğu görülmektedir. Bu durumun seçilen kaynak devri ve kaynak sürtünme süresinin AISI 304 ve AISI 5140 çeliklerinin sürtünme kaynăg 1 esnasında yeterli malzeme viskozunun oluşturamamasından kaynaklandığı düşünülmektedir. Ayrıca AISI 5140 çelik tarafinda daha fazla malzeme deformasyonun olması plastik şekil değişimin bu malzeme de daha yüksek olmasındandır. S5 nolu numunenin kaynak arakesiti incelendiğinde ADB bölgesinin net bir şekilde oluştuğu görülmektedir. Yüksek devir ve yüksek sürtünme süresin de yapılan birleştirmede difüzyonun oluşumu için uygun sürenin ve devirin olması nedeniyle difüzyonun geniş bir bölgede oluşmasını ve ayrıca yığma basıncının etkisiyle de viskoz duruma gelmiş bu plastik deformasyona uğrayan bölgenin, kaynak arakesitin de basınç etkisi ile uzaklaştığı düşünülmektedir.

Şekil 8'de S1 ve S5 nolu numunelerin kaynak arakesitinin 1000x büyütme ile daha detaylı bir şekilde verilmiştir.
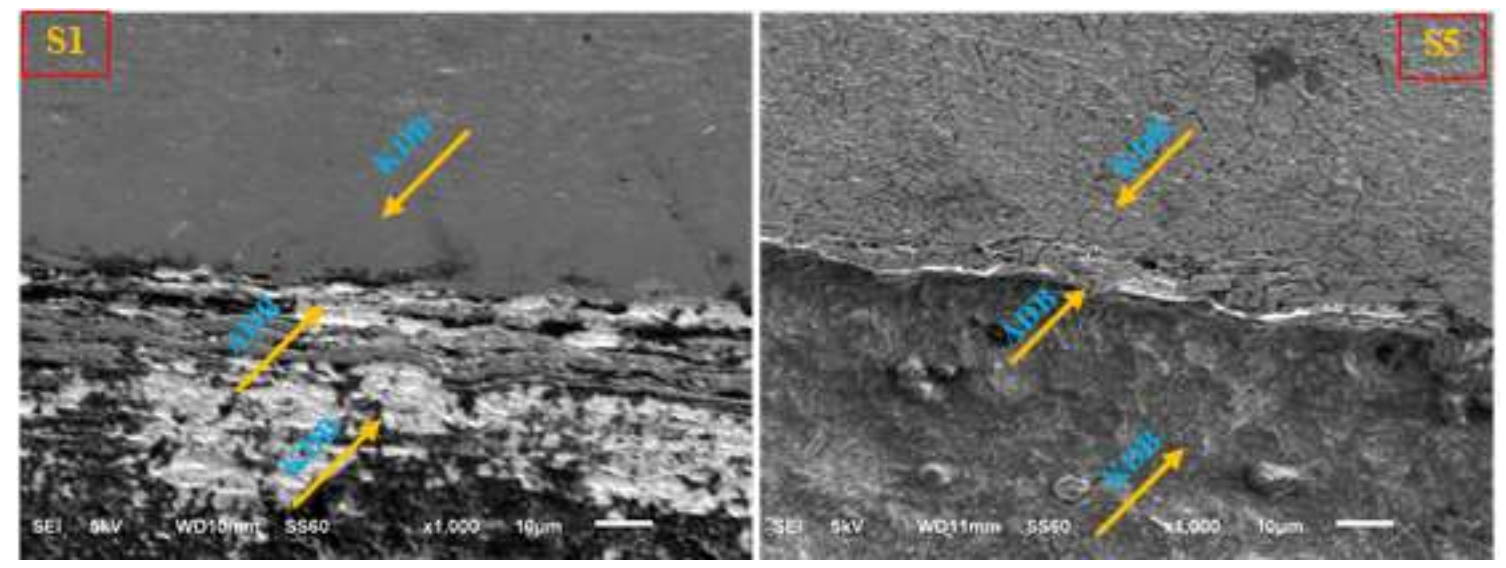

Şekil 8. S1 ve S5 nolu numunelerin SEM görüntüleri 
Şekil 8'deki S1 ve S5 nolu numunelerin SEM görüntülerinde, S5 nolu numunenin kaynak arakesiti yüzeyinin kısmen deformasyona uğramış bölgesinde ince taneli yapıların oluştuğu ve bu tanelerin kaynak dönme devri ile birlikte oluşan ısının etkisiyle dönme yönünde kısmen küçülmüş plaka şeklinde yönelmiştir. Aşırı deformasyon bölgesin de AISI 304 ve AISI 5140 çeliklerinin arasında tam bir birleşmenin olduğu ve viskoz duruma gelen malzemenin yığma basıncın etkisiyle dışarıya doğru yöneldiği görülmektedir. Ancak S1 nolu numunenin aşırı deformasyona uğramış bölgesin de AISI 5140 çeliğinden malzeme kopmaların olduğu fakat S5 nolu numunede olduğu gibi uygun malzeme viskozunun oluşmadığı ve bundan dolayı tam olarak yapışmayan bölgelerin meydana geldiği görülmektedir. Ayrıca sürtünme kaynağı ile ilgili yapılan çalışmalar irdelendiğinde; Meriç ve ark. (2008) kaynak parametrelerinin birleşme bölgeleri üzerinde önemli bir etkiye sahip olduklarını ve ayrıca yapılan sürtünme kaynak işlemlerinde plastik deformasyonun yumuşak olan malzeme tarafindan daha fazla olduğunu belirtmişlerdir [12]. Sarsılmaz ve ark. (2017) yaptıkları sürtünme kaynağının mikroyapı incelemelerinde sürtünme devrinin ve sürtünme süresinin artmasıyla kaynak birleşme bölgelerinde malzeme viskozunun artırdığını ve bu durumun kaynağı yapılacak malzemelerin birleşme bölgeleri üzerinde önemli bir etkiye sahip olduklarını belirtmişleridir [13].

\subsection{Mikrosertlik ölçümleri}

S1 ve S5 nolu numunelerin kaynaklı bağlantılarından alınmış mikrosertlik ölçümleri Şekil 9'da verilmiştir.

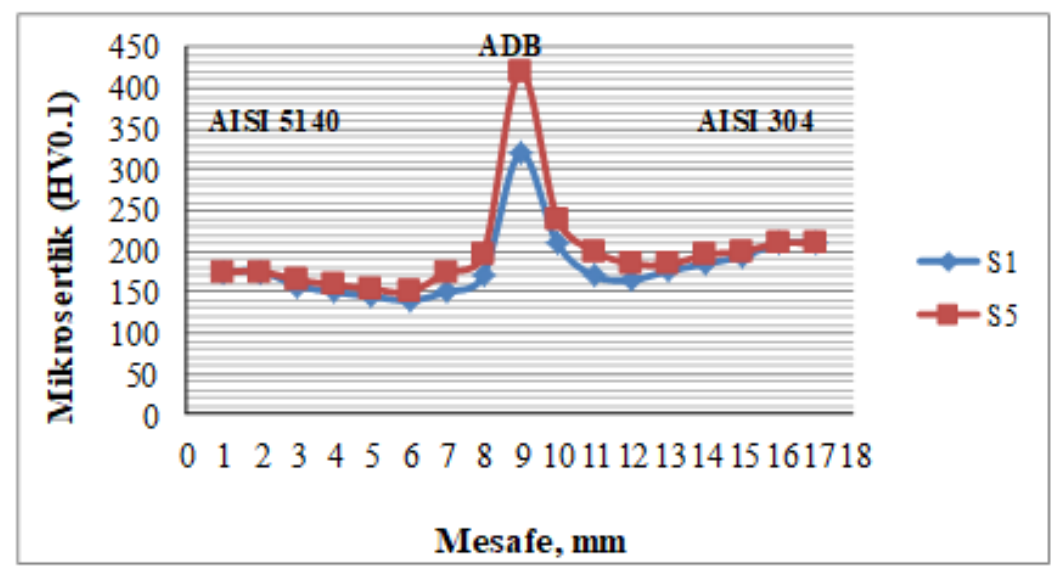

Şekil 9. S1 ve S5 nolu numunelerin mikrosertlik ölçümleri

S1 ve S5 nolu numunenin mikrosertlik ölçümlerinde benzer karakteristik davranışlar gösterilmiştir. AISI 304 paslanmaz çelik ve AISI 5140 çelik ana malzemelerinden aşırı deformasyon bölgelerine doğru gidildiğinde 1 sı tesiri etkisi altındaki bölgede (ITAB) sertliklerin azaldığı kaynak ana malzemesine (ADB) doğru gidildikçe tekrardan sertlik değerlerinde artışların olduğu görülmektedir. En yüksek sertlik değeri S1 ve S5 nolu numunelerinin aşırı deformasyona uğramış bölgelerinde sırasıyla $320 \mathrm{HV}$ ve $420 \mathrm{HV}$ olarak elde edilmiştir. En yüksek artışların ADB'de elde edilmesinin nedeni ise sürtünme kaynağı esnasında tanelerin parçalanıp incelenmesi ve düşük sıcaklıklarda termo-mekanik karıştırma sonucu plastik deformasyona bağlı olarak yeniden kristalleşme ile alakalı olduğu düşünülmektedir. Ünal ve ark. [5]; Şahin ve ark. [6], Sathiyan ve ark. [8], Palanivel ve ark. [14] ve Wang ve ark. [15] yaptıkları çalışmalarında dönme devrinin artmasıyla kaynak birleşim bölgelerinin sertliğini artığını ve kaynak merkezinde maksimum sertliğin meydana geldiğini ve ayrıca ITAB bölgelerinde kaynak setliklerinin düştüğünü belirtmişlerdir.

\section{3. Çekme test sonuçları}

ASTM-E8 standardına göre hazırlanan çekme numunelerin kuvvet-deplasman (uzama) grafiği şekil 10 'da ve çekme sonrası oluşan kopma bölgelerin gösterimi ise Şekil 11'de verilmiştir. 


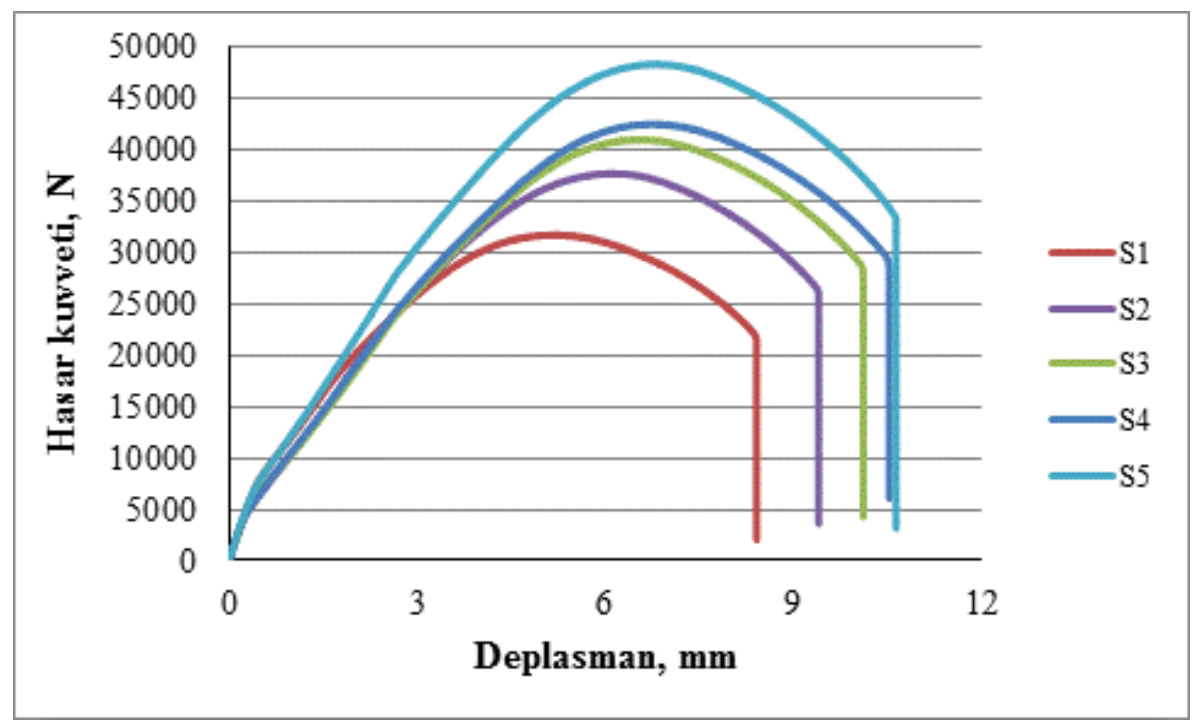

Şekil 10. 1500, 1700 ve 1900 dev/dak devir ve 4, 6 ve 8 saniye sürtünme sürelerinde yapılan birleştirmelerin çekme testleri

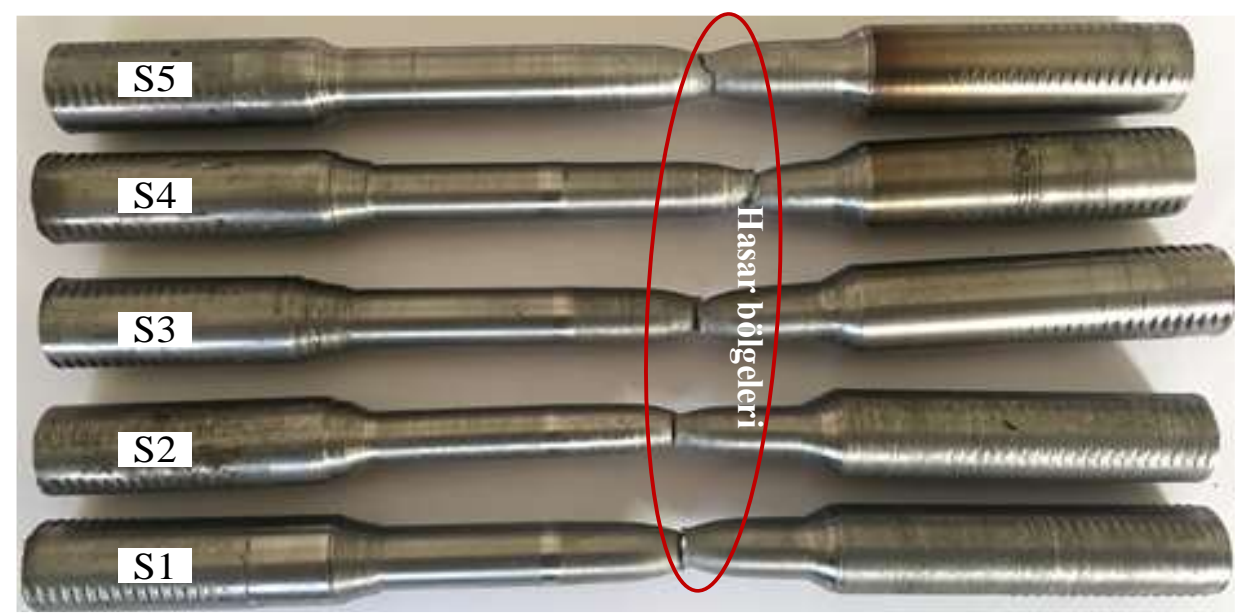

Şekil 11. Çekme testleri sonrası numunelerin kırılma yüzeyleri

Shimadzu marka çekme test cihazıyla $1 \mathrm{~mm} /$ dak test ilerleme hızı ile yapılan deney sonuçlarında en yüksek ve en düşük çekme kuvveti S5 nolu numune de 48406.25, S1 nolu numunesinde ise 31789.06 N olarak elde edilmiştir. Mikroyapı ve SEM görüntülerinde yüksek devir ve yüksek sürtünme sürelerinde birleşme bölgelerinde iyi bir birleşmenin meydana geldiği görülmüştü. Çekme test sonuçları da bu duruma benzerlik göstermiştir. Ayrıca çekme testlerine bütün kopmalar AISI 5140 çelik malzemesinde meydana gelmiştir (Şekil 11). Bütün kopmalar sünek formada oluşmuştur. Bütün kaynakların başarılı bir şekilde yapılmıştır. Çünkü bütün kopmalar AISI 5140 çelik malzemesinde meydana gelmiştir. Benzer sonuçların Özdemir ve ark. (2007) yapıkları çalışmalarında maksimum çekme gerilmesinin en iyi mikyoyapı ve en yüksek mikrosertlik değerlerinin elde edildiği sürtünme kaynağı için seçilen en yüksek sürtünme devrinde elde edildiğini belirtmişlerdir [16].

\section{Sonuç}

AISI 304 paslanmaz çeliği ve AISI 5140 çelik malzemeleri 1500, 1700 ve 1900 dev/dak devirlerde ve 4, 6 ve 8 saniye sürtünme sürelerinde sürtünme kaynağı metodu ile başarılı bir şekilde birleşimi yapılmıştır. Kaynak sonrası kaynak arakesitinde meydana gelen yapıları görmek için mikroyapı ve SEM görüntüleri alınmıştır. Ayrıca sürtünme birleşimlerinin mekanik özeliklerini öğrenmek içinde mikrosertlik ölçümler ve çekme test deneyleri yapılmıştır. Elde edilen sonuçlar aşağıda verilmiştir. 
a- Mikroyapı ve SEM görüntülerinde kaynak arakesitlerinden alınan numunelerde $1900 \mathrm{dev} / \mathrm{dak}$ ve 8 saniye sürtünme sürelerinde yapılan kaynaklarda daha iyi bir birleşme yüzeyi elde edilmiştir.

b- Mikrosertlik sonuçlarında en yüksek ve en düşük sertlik değerleri sırasıyla S1 ve S5 nolu numunelerde 320 ve $420 \mathrm{HV}$ olarak elde edilmiştir.

c- Çekme test sonuçlarında en yüksek kuvvet hasarı ve deplasman (uzama) S5 nolu numunede $48406.25 \mathrm{~N}$ ve $10.633 \mathrm{~mm}$ olarak elde edilmiştir.

d- Çekme test sonuçlarında bütün numuneler plastik şekil değişimi göstererek AISI 5140 çelik malzemesinde kopmalar gerçekleşmiştir.

\section{Yazarların Katkısı}

Çalışmada tüm katkı yazara aittir.

\section{Çıkar Çatışması Beyanı}

Yazarlar arasında herhangi bir çıkar çatışması bulunmamaktadır.

\section{Araştırma ve Yayın Etiği Beyanı}

Yapılan çalışmada araştırma ve yayın etiğine uyulmuştur.

\section{Kaynaklar}

[1] Kırık I., Ozdemir N., Sarsılmaz F. 2012. Microstructure and Mechanical Behaviour of Friction Welded AISI 2205/AISI 1040 Steel Joints. Materials Testing, 54: 683-687.

[2] Lucas W. 1971. Process Parameters and Friction Welds. Met. Cons. and British Welding Journal, 71: 293-297.

[3] Çalıgülü U., Orhan A., Gür A.K. 2007. Sürtünme Kaynak Yöntemiyle Birleştirilmiş AISI 420/AISI 1010 Çelik Çiftinde Çevresel Hızın Mikroyapı Özelliklerine Etkisi. Fırat Üniversitesi Fen ve Mühendislik Bilimleri Dergisi, 19: 583-592.

[4] Kaluç E. 2004. Kaynak teknolojisi el kitabı. MMO Yayınları, Ankara, 356-358.

[5] Ünal E., Karaca F., Sarsilmaz F. 2019. Investigation of Interface Microstructure Properties of AISI 3161 /AISI 4140 Steel Couple Welded by Friction Welding Process. Journal of the Faculty of Engineering and Architecture of Gazi University, 34 (2): 701-708.

[6] Sahin M., Akata H.E. 2004. An Experimental Study on Friction Welding of Medium Carbon and Austenitic Stainless Steel Components. Industrial Lubrication and Tribology, 56 (2): 122-129.

[7] Chludzinski M., Santos R.E.D., Pissantib D.R., Kroeff F.C., Matteib F., Dalpiazc G., Paesc M.T.P. 2019. Full-Scale Friction Welding System for Pipeline Steels. Journal Mater Res Technol., 8 (2): 1773-1780.

[8] Sathiya P., Aravindan S., Haq A.N. 2008. Some Experimental Investigations on Friction Welded Stainless Steel Joints. Materials and Design, 29: 1099-1109.

[9] Taban E., Gould J.E., Lippold J.C. 2010. Dissimilar Friction Welding of 6061-T6 Aluminum and AISI 1018 Steel: Properties and Microstructural Characterization. Materials and Design, 31: 2305-2311.

[10] Celik S., Ersozlu I. 2009. Investigation of The Mechanical Properties and Microstructure of Friction Welded Joints Between AISI 4140 And AISI 1050 Steels. Materials and Design, 30: 970976.

[11] Emre H.E., Kaçar R. 2013. Sürtünme Kaynağı İle Birleştirilen Sondaj Borularının Yorulma Davranışları. Gazi Üniversitesi Müh. Mim. Fak. Dergisi, 28 (2): 417-426.

[12] Meriç C., Köksal N.S., Erdoğan M.T., Okur A. 2008. Sürtünme Kaynăğ İle Birleştirilmiş Farklı Malzemelerin Kaynak Bölgesinin İncelenmesi. C.B.Ü. Fen Bilimleri Dergisi, 4 (2):135-144.

[13] Sarsılmaz F., Kırık İ., Ay M. 2017. Sürtünme Kaynak Yöntemi İle Birleştirilmiş SCR 420/AISI 1040 Çelik Çiftlerinin Ara-Yüzey Mikroyapı Özelliklerinin İncelenmesi. Fırat Üniversitesi Müh. Bil. Dergisi, 29 (2): 51-56. 
[14] Palavinel R., Dinaharan I., Laubscher R.F. 2019. A Comparative Study on Microstructure and Mechanical Properties Between Friction and Laser Beam Welded Titanium Tubes. OptikInternational Journal for Light and Electron Optics, 177: 102-111.

[15] Wang X., Li W., Ma T., Yanga X., Vairisa A. 2019. Effect of Welding Parameters On the Microstructure and Mechanical Properties of Linear Friction Welded Ti-6.5Al-3.5Mo-1.5Zr0.3Si Joints. Journal of Manufacturing Processes, 46: 100-108.

[16] Özdemir N., Sarsılmaz F., Hasçalık A. 2007. Effect of Rotational Speed on The Interface Properties of Friction-Welded AISI 3041 to 4340 Steel. Materials and Design, 28: 301-307. 